International Journal of Current Micro6iology and Applied Sciences

ISSN: 2319-7706 Volume 9 Number 2 (2020)

Journal homepage: http://www.ijcmas.com

Original Research Article

https://doi.org/10.20546/ijcmas.2020.902.122

\title{
Salmonellosis in Captive Asian Elephants (Elephas maximus) of TamilNadu State, India
}

\author{
A. Senthilkumar ${ }^{1 *}$, M. G. Jayathangaraj ${ }^{2}$, A. Valli ${ }^{3}$ A. Thangavelu ${ }^{4}$, \\ S. Gomathinayagam ${ }^{5}$ and N. Sribalaji ${ }^{6}$ \\ ${ }^{1}$ Farmers Training Centre, Theni-625 53, India \\ ${ }^{2}$ Department of Veterinary Clinical Medicine and Therapeutics, \\ Madras Veterinary College, Chennai-600007, India \\ ${ }^{3}$ Institute of Animal Nutrition, PGRIAS, Kattupakkam, Chennai-600007, India \\ ${ }^{4}$ Department of Veterinary Microbiology, ${ }^{5}$ Department of Veterinary Parasitology, \\ Madras Veterinary College, \\ Chennai-600007, India \\ ${ }^{6}$ MSRS, Pottaneri, India \\ *Corresponding author
}

Keywords

Asian elephants-

diarrhoea-

Salmonella

Article Info

Accepted:

08 January 2020

Available Online:

10 February 2020
The main objective of the present study was isolation and molecular identification of Genus Salmonella in diarrheic captive Asian elephants (Elephas maximus) of Tamil Nadu state. Isolation and identification of Genus Salmonella was carried out in both fresh water and dung samples from diarrhoeic cases of captive elephants $(\mathrm{n}=8)$, using culturing method and PCR technique. Out of the dung $(n=8)$ and water $(n=8)$ samples, $25.00 \%(n=2)$ of water samples as well as $25.00 \%(n=2)$ of the dung samples were found to be positive for Genus Salmonella organisms. A red coloured colony-growth on modified Brilliant Green Agar and Colourless colony with Black spot at centre indicated the growth of Salmonella. Molecular identification of Genus Salmonella by Polymerase Chain Reaction (PCR), the amplicon size was $260 \mathrm{bp}$. These findings in this study indicated the need for supply of good quality water to the captive elephants, in order to minimize the possible incidences of contamination of Genus Salmonella. 


\section{Introduction}

Throughout the world, infectious enteritis is the most significant cause of morbidity and mortality in wild animals under captive conditions and it can be caused by many pathogens including viruses, protozoa and bacteria (Izzo et al., 2011). Among the bacteria genus Salmonella infections are considered by many to be the leading cause of diarrheal disease in elephants (Janssen et al., 1984).The gastrointestinal tract of both warm and cold-blooded animals is the reservoir for Salmonella organisms, which may be commensals and part of the normal flora of the gastrointestinal tract. The organisms are shed intermittently in the feces and may survive for months in soil, and will even multiply in water.

Any contamination of feeds or water may allow ingestion of the organisms. Whether disease develops in the new host (elephant) depends on the infectious dose, resistance of the host to colonization within the gastrointestinal tract, and serovar of the salmonella (Morner,2001). Water becomes a suitable factor in transmission of infectious enteric diseases and could endanger health and life of humans as well as animals. In diarrhoeic elephants, water and dung samples test is the only way to evaluate the presence of bacteria in drinking water.

There is paucity of information related to the examination of drinking water in, used by enteric cases of elephants under captive conditions. Hence analysis of drinking water and dung samples, the incidences of occurrence of Salmonella organisms in these mega herbivores by culture and / or PCR technique will be much helpful in formulating the suitable management measures that are required for the successful management and preventative measures of captive Asiatic elephants.

\section{Materials and Methods}

Water and dung samples were collected from eight diarrheic elephants during the study period (Table-1).Water samples were collected in $250 \mathrm{ml}$ sterile and clear air tight containers and were subsequently sealed, by using parafilm in order to avoid the contamination.

Similarly, fresh dung samples were collected in sterile containers and samples were transported to the laboratory in igloo box containing ice bags in order to maintain the samples as fresh as possible. Isolation and identification of Genus Salmonella was carried out in both water and dung samples, using standard microbiological media (Modified Brilliant Green agar (Himedia), Salmonella Shigella agar (Himedia), Selenite Broth (Himedia) and Nutrient Agar (Himedia)) and PCR technique.

\section{Isolation and identification of Genus Salmonella in water and dung samples}

Selenite broth enriched culture was streaked into modified brilliant green agar (BGA) incubated at $37^{\circ} \mathrm{C}$ for 24 hours and was observed for the development of colonies. It was sub-cultured on Nutrient Agar and was later transferred to slant for further process. DNA was extracted from positive cultures using DNA Mini kit as per manufactures protocol.

The extracted DNA template used for confirmation of Salmonella by PCR. The target gene selected for PCR amplification was stn gene (Salmonella enterotoxin) for Salmonella Sp. (Makino et al., 1999). This primer was procured from Ocimum Biosciences and details of primers were given below: 


\begin{tabular}{|l|c|c|}
\hline \multicolumn{1}{|c|}{ Gene Sequence $\left(\mathbf{5}^{\prime}-\mathbf{3}^{\prime}\right.$ ) } & $\begin{array}{c}\text { Amplicon size } \\
\text { (bp) }\end{array}$ & Target Reference \\
\hline $\begin{array}{l}\text { StnF: CTT TGG TCG TAA AAT AAG } \\
\text { GCG }\end{array}$ & 260 & (Makino et al., 1999) \\
\hline R: TGC CCA AAG CAG AGA GAT TC & & \\
\hline
\end{tabular}

Initial denaturation at $94^{\circ} \mathrm{C}$ for 5 minutes, followed by 30 cycles of denaturation at $94^{\circ} \mathrm{C}$ for 30 seconds, annealing at $53^{0} \mathrm{C}$ for 40 seconds and primer extension at $74^{\circ} \mathrm{C}$ for 40 seconds and was followed by final extension at $72^{\circ} \mathrm{C}$ for 8 minutes. The amplified PCR products were analysed $1.5 \%$ agarose gel.
Out of the dung $(n=8)$ and water $(n=8)$ samples, pertaining to diarrhoeic cases examined (Table- 2) $25.00 \%(n=2)$ of water as well as $25.00 \%(n=2)$ of the dung samples were found to be positive for Genus Salmonella organisms.

\section{Results and Discussion}

Table.1 Places of water and dung samples collected

\begin{tabular}{|r|l|l|l|}
\hline S. No. & \multicolumn{1}{|c|}{ Places } & \multicolumn{2}{|c|}{ Type of Samples } \\
\hline $\mathbf{1}$ & Ilanji & Dung & Water \\
\hline $\mathbf{2}$ & Tirupugalur & & \\
\hline $\mathbf{3}$ & Virudhunagar & & \\
\hline $\mathbf{4}$ & Nagore & \\
\hline $\mathbf{5}$ & Tiruvaiyaru & & \\
\hline $\mathbf{6}$ & Tirukkurungudi & & \\
\hline $\mathbf{7}$ & Eraittaitirupathi & & \\
\hline $\mathbf{8}$ & Tanjavore & \\
\hline
\end{tabular}

Table.2 Presence of Genus Salmonella in water and dung samples

\begin{tabular}{|c|c|c|c|}
\hline S. No & Place & Water & Dung \\
\cline { 3 - 4 } & & Salmonella & Salmonella \\
\hline $\mathbf{1}$ & Virudhunagar & - & - \\
\hline $\mathbf{2}$ & Tirupugalur & - & - \\
\hline $\mathbf{3}$ & Nagore & + & + \\
\hline $\mathbf{4}$ & Tiruvaiyaru & - & - \\
\hline $\mathbf{5}$ & Tirukkurungudi & - & - \\
\hline $\mathbf{6}$ & Erattaitirupathi & - & - \\
\hline $\mathbf{7}$ & Ilanji & - & - \\
\hline $\mathbf{8}$ & Tanjavore & + & + \\
\hline
\end{tabular}




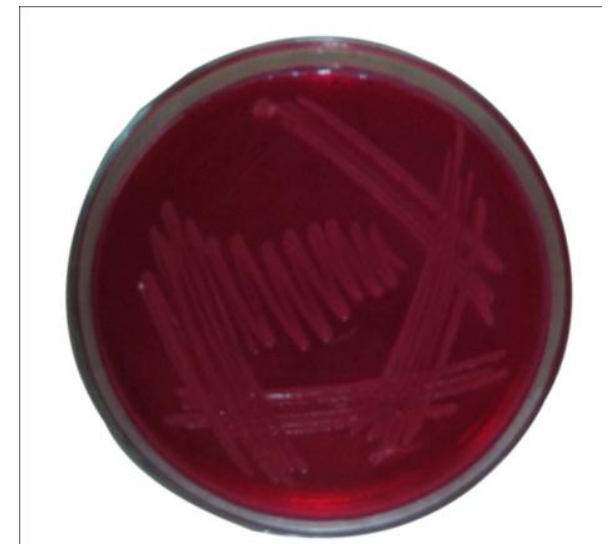

Plate.1 Isolation and identification of genus salmonella Modified Brilliant green agar Salmonella (Pink color colonies)

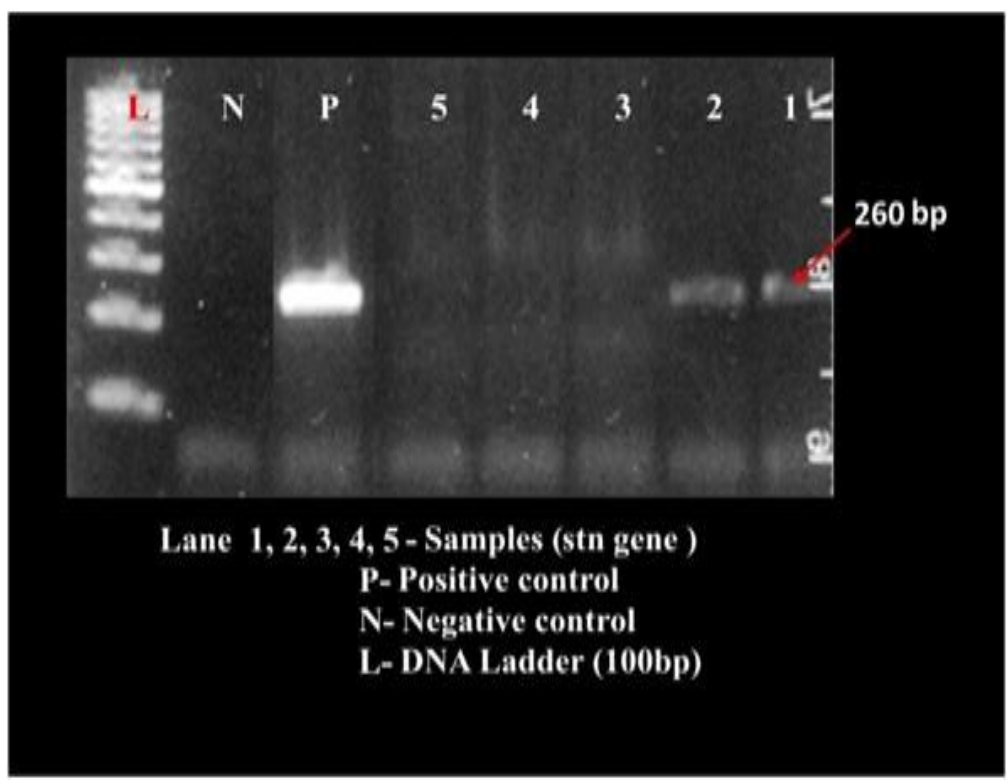

PCR - Identification of Genus Salmonella

Isolation of Genus Salmonella by Culture, a red coloured colony-growth on Brilliant Green Agar and colourless colony with Black spot at centre indicated the growth of Salmonella as shown in Plate 1. Molecular Identification of Genus Salmonella by Polymerase Chain Reaction (PCR), the amplicon size was 260 bp as shown in Plate 2. The culture result coincided with PCR results, with regard to the confirmation of Genus Salmonella organisms.

The confirmation of Genus Salmonella organisms by PCR test carried out in this study was in agreement with the findings of Momtaz et al., (2013) which stated that the Polymerase Chain Reaction assays could be an extremely safe, fast, sensitive and specific approach and in order to monitor the safety of the drinking water and in addition to the faecal contamination as well as the contamination of drinking water by sewage also needed to be ruled out. In this regard, the application of PCR assay towards rapid detection of microbes like Salmonella organism was revealed by Moussa et al., (2010).The microbial organisms in water samples during the present study were in 
agreement with the findings presented by Anwar et al., (2010) and Morinigo et al., (1986) also quoted that since the dissemination of faecal microorganisms was incompletely understood, satisfactory methods of control could not be designed and the principal health related risk was quoted to be the presence of faecal pathogenic bacteria which led to the occurrence of enteric diseases.

The encountering of enteric infections in two elephants out of eight animals in this study was supported by Momba et al., (2006) who opined that among the pathogens disseminated in water sources, the enteric pathogens were the ones which were most frequently encountered and the enteric pathogens such as Salmonella and other diarrheic were the usually transmitted ones by the ingestion of contaminated water and foods and the enteric bacteria were reportedly causative agents of various diseases and their complications.

Encountering the Genus Salmonella during this study was in agreement with the findings furnished by Morinigo et al., (1986) who further quoted that Salmonellae were the pathogenic microorganisms most frequently found in the polluted water and could also be found as free-living forms which proliferated under normal environmental conditions. In this regard, Teplitski (2009) quoted about identification of Salmonella organisms in different animal farms and reiterated that proper utilization and composting of animal wastes were the important steps for reducing the contamination of Salmonella for the breaking the cycle of reinfection.

In connection with the encountering of Salmonella in water during this study, it appeared to be noteworthy to quote findings of Ramteke et al., (1992) who stated that in the control of diarrhoeal diseases which were responsible for considerable morbidity and mortality, priority must be given to the supply of safe drinking water and this could be ensured only by regular periodical examinations of the drinking water that was supplied to these mega herbivores routinely in all the places or temples that were associated with the management of the captive elephants.

Hence, it could be finally suggested that the consistent but at the same time, periodical examination of drinking water samples and proper disinfection process of the water storage places or containers or supply routes should be carried out in a systematic manner to prevent the spread of pathogenic microbial organisms like Salmonella organisms.

However, in this regard it was noteworthy to mention the report furnished by Teplitski (2009) who opined that infected animals with organisms like Salmonella were not always visibly sick and however, these asymptomatic carrier animals shed billions of virulent organisms in each ounce of their faeces. Hence, in future, it was suggested as one of the management related measures to rule out the presence of these micro-organisms, even in the elephants which are not visibly sick.

\section{References}

Anwar, M.S., Lateef,S and Siddiqi,G.M., 2010.Bacteriological quality of drinking water in Lahore. Biomedical, 26: 66-69.

Izzo,M.M.,Kirkland,P.D.,Mohler,V.L.,Perkin s,N.R.,Gunn,A.A.,House,J.K.,2011.Prev alence of major enteric pathogens in Australians dairy calves with diarrhea. Australians Vet. Journal 89(5):167-173.

Janssen, D.L., Karesh, W.B., Cosgrove, G.E and Oosterhuis, J.E., 1984. Salmonellosis in a herd of captive elephants. J Am Vet Med Assoc .,185(11):1450-1451.

Makino,S., Kurazono,H., Chongsanguam,M., 
Hayashi,H., Cheun,H., Suzuki,S and Shirahata, T.,1999. Establishment of PCR system specific to Salmonella spp. and its application for the inspection of food samples. J. Vet. Med. Sci. 61: 1245-1247.

Momba, M.N.B., Malakate,V.K and Theron,J., 2006. Abundance of pathogenic Escherichia coli, Salmonella typhimuriumand Vibrio cholera in Nkonkobe drinking water sources. $J$. Water and Health. 4(3): 289-296.

Momtaz, H., Dehkordi, F.S., Rahimi,E and Asgarifar, A.,2013. Detection of Escherichia coli, Salmonella species and Vibrio cholera in tap water and bottled drinking water in Isfahan. IranBMC Public Health 13: 556-562.

Morner, T., 2001. Salmonellosis. In Williams, E.S., ed. Infectious Diseases of Wild Mammals,

3rd ed. Ames, Iowa State University Press, pp. 505-507.

Morinigo, M.A., Borrego,J.J and Romero, P.,1986. Comparative study of different methods for detection and enumeration of Salmonella spp. In natural waters.
Journal of Applied Bacteriology 61: 169-176.

Moussa, I.M., Gassem, M.A., AI-Doss, A.A., Mahomoud,W.A.S., and Mawgood,A.L.A., 2010. Using molecular techniques for rapid detection of Salmonella serovars in frozen chicken and chicken products collected from Riyadh, Saudi Arabia. African Journal of Biotechnology 9(5): 612-619.

Ramteke, P.W., Bhattacharjee, J.W., Pathak, S.P and Kaira,N.,1992. Evaluation of coliforms as indicators of water quality in India. Indian. J. Anim. Sci., 71 (11): 1043-1044.

Rarnteke, P.W., Bhattacharjee, J.W., Pathak, S.P and Kalra, N.,1992. Evaluation of coliforms as indicators of water quality in India. J. Appl.Bacteriol. 72: 3512-3513.

Teplitski, M., 2009. E.coli and Salmonella on animal farms: sources, survival and management. SL-239, Fact sheet of the Soil and Water Science Department, Florida Cooperative Extension Service, Institute of Food and Agricultural Sciences, University of Florida.

\section{How to cite this article:}

Senthilkumar. A., M. G. Jayathangaraj, A. Valli, A. Thangavelu, S. Gomathinayagam and Sribalaji. N. 2020. Salmonellosis in Captive Asian Elephants (Elephas Maximus) of TamilNadu State. Int.J.Curr.Microbiol.App.Sci. 9(02): 1045-1050.

doi: https://doi.org/10.20546/ijcmas.2020.902.122 